\title{
Multiculturalismo e etnicidade: os quilombolas e a construção da cidadania no Brasil contemporâneo
}

Ana Maria Martins Amorim ${ }^{1}$

\section{Resumo}

O presente artigo busca analisar a relação histórica entre etnia e cidadania no contexto do multiculturalismo nas três últimas décadas do século XX, particularmente no Brasil, com o propósito de identificar novas concepções e experiências de cidadania que resultam das demandas pelo reconhecimento da diversidade e das conquistas sociais, políticas e jurídicas. Antes baseada em direitos iguais e comuns a todos, a cidadania contemporânea é construída com base nos direitos diferenciados das minorias.

Palavras-chave: Multiculturalismo. Etnicidade. Cidadania. Comunidades remanescentes de quilombos.

\section{Introdução}

O mundo contemporâneo tem sido palco do renascimento de diversas manifestações nacionalistas e étnicas. Conflitos surgem como tentativa de recuperar e rever a história, exigindo a ampliação de direitos e políticas públicas em resposta às lutas e reivindicações dos grupos minoritários. Os direitos relativos a essas demandas no contexto multicultural assumem características que se destacam da noção universalista dos direitos humanos que, por si só, são incapazes de atingir algumas questões ligadas à problemática da diversidade.

1 Graduada em Ciências Sociais pela Universidade de Brasília e Especialista em História, Sociedade e Cidadania - UniCEUB/ICPD. Este artigo foi elaborado a partir de monografia apresentada na pós-graduação lato sensu e orientada pela profa. Rosana Ulhôa Botelho. 
Na contemporaneidade, a cidadania é constituída por práticas, concepções e direitos que a diferenciam historicamente da cidadania sobre as bases de uma identidade igualitária. Os direitos comuns de cidadania não podem acomodar as necessidades dos grupos minoritários diversificados, pois “[...] uma cidadania plenamente integradora deve considerar estas diferenças" (KYMLICKA, 1995, p. 248).

No final do século XX, as identidades étnicas são transformadas no cenário das relações globais e se tornam um grande desafio à cidadania. A pertença étnica surge "[...] como categoria pertinente para a ação social e a crescente tendência de fazer derivar dela lealdades e direitos coletivos" (POUTIGNAT; STREIFF-FENART, 1998, p. 26). As etnias ressurgem como sujeitos sociais no cenário multicultural, com o propósito de reivindicar direitos e políticas que contribuam para uma sociedade mais justa e inclusiva. Entretanto, o reverso muitas vezes ocorre em nome da afirmação da etnicidade, ou seja, na luta por reconhecimento e direitos, grupos minoritários se constituem baseados em seu caráter étnico.

O presente artigo busca entender a relação histórica entre etnia e cidadania no contexto do multiculturalismo a partir das duas últimas décadas do século XX. Com esse propósito, enfoca o debate contemporâneo sobre a cidadania, suas transformações e os desafios que lhes são impostos pela presença de novos sujeitos políticos, no caso, os grupos étnicos. Por meio de uma sistematização da bibliografia feita à luz de indagações que articulam a cidadania ao multiculturalismo e à etnicidade, este trabalho destaca a influência dos grupos étnicos para a instituição e ampliação da cidadania na realidade multicultural brasileira.

A pesquisa bibliográfica desenvolveu-se com base em resumos, análises e interpretação de livros, teses, artigos e sites, apoiada, principalmente, pelos trabalhos de Charles Taylor, Will Kymlicka e Poutignat e Streiff-Fenart, como também o livro Mocambo: Antropologia e História do processo de formação quilombola (2006), de José Maurício Arruti, escolhido como fonte para a descrição e interpretação do processo de constituição de grupos étnicos e suas implicações na formação da cidadania multicultural brasileira. 


\section{Aspectos significativos do debate}

\subsection{Identidade e reconhecimento}

O século XX é marcado pela intensificação dos fluxos migratórios e das mobilizações nacionais, acompanhados pela afirmação das identidades étnicas e nacionais. Após a Guerra Fria, “[...] as reivindicações dos grupos étnicos e nacionais passaram ao primeiro plano da vida política, nos âmbitos nacional e internacional" (KYMLICKA, 1995, p. 267). Surgem as "políticas da diferença" como respostas às aspirações dos grupos minoritários, organizados e mobilizados na luta por direitos diferenciados.

Segundo Woodward (2000), a migração intensificada pela globalização tem produzido identidades plurais e, ao mesmo tempo, identidades negadas. Os particularismos locais representam identidades étnicas e nacionais e compõem um panorama complexo e conflituoso no qual o ser humano procura o reconhecimento da identidade de seu grupo. Portanto, o papel da identidade torna-se essencial para compreender o processo de ressurgimento dessas minorias e das respectivas formas de mobilização.

Por meio da identidade, conhecemos, agimos e damos respostas ao mundo; definimos o que é comum, habitual e natural em contraposição ao que não o é. Surgem as noções de classe, gênero, grupo, etnias, nacionalidades, produzindo práticas sociais e valores que, no desenrolar da vida diária, incluem e excluem indivíduos no contexto social. As identidades constroem e sintetizam a noção de coesão social e pertencimento.

A afirmação de uma identidade é histórica, ou seja, está localizada em um tempo e espaço específicos, nos quais a organização social estabelece um sistema de classificação e diferenciação entre pessoas, grupos, classes, gênero, nações; enfim, estabelece o "nós” e os "outros”. Segundo Woodward (2000, p. 39), “[...] a marcação da diferença é crucial no processo de construção das posições de identidade". Essa diferença é reproduzida por meio de sistema de símbolos que estabelece um 
sentido e posições dentro de uma cultura. No cotidiano, os homens se relacionam e produzem os sistemas simbólicos e classificatórios que vão dar sentido e constituir suas identidades em determinado lugar e tempo plenos de significados.

A construção da identidade, portanto, é resultado de interações e inter-relações que se desdobram dentro de determinado contexto: a cultura. Em síntese, pode-se afirmar que o processo de constituição da identidade é relacional, simbólico, social, dinâmico e histórico. Tais concepções vão ao encontro das reflexões de Charles Taylor (1994), que demonstram a estreita relação entre identidade e reconhecimento. O reconhecimento da identidade é uma forma de cultivar a dignidade e autoestima dos grupos excluídos no interior do espaço público. As identidades não são categorias rígidas, mas são construídas no diálogo aberto, melhor dizendo, o sujeito se constitui na relação com o outro e depende de relações dialógicas com os outros.

De acordo com a concepção dialógica, a identidade do indivíduo assume forma somente no cotidiano, por meio da educação e aprendizagem, com a interiorização do sistema de valores e das normas de conduta, na interação social. A intersubjetividade, a afiliação e o sentimento de pertença são essenciais para a constituição do indivíduo e não um obstáculo à sua realização.

Sendo assim, a realização do indivíduo exige a construção de laços, afetividade e enraizamento social e histórico, afirma Taylor (1994), cuja abordagem difere da visão filosófica clássica, na qual o indivíduo é visto em sua essencialidade como um ser moral e racional, autônomo e pleno, inserido em uma dimensão abstrata.

O reconhecimento da diferença significa ir além de rejeitar a alteridade, significa aceitar a diversidade como a expressão da condição humana, melhor dizendo, reconhecer o outro e reconhecer-se, tornando possível a pluralidade humana. Ao buscar o reconhecimento, o homem aspira à sua própria dignidade ou aquela de seu grupo cultural ou étnico. O reconhecimento se torna um conceito fundamental para a compreensão da identidade, pois qualquer uma das formas de identidade, tomada como característica essencial do ser humano, se completa ao ser reconhecida e aceita (TAYLOR, 1994). 
Na dimensão social, em função das relações de discriminação e exclusão, as identidades podem ser deformadas e depreciadas, causando danos e prejuízos aos indivíduos e grupos segregados. Taylor (1994) assinala que reconhecimento inadequado pelo outro pode levar a distorções uma pessoa, condenando-a a uma identidade negativa que se reflete na imagem de inferioridade e desprezo, o que se torna “[...] um dos instrumentos mais poderosos de sua própria opressão" (p. 46). $\mathrm{O}$ não reconhecimento, além do desrespeito, imprime em suas vítimas as marcas da inferioridade, baixa autoestima e submissão.

Ao serem reconhecidas, a identidade e as diferenças propiciam o enriquecimento do indivíduo e do grupo. No entanto, como alerta Semprini (1999, p. 104), em situações em que não são reconhecidas, as diferenças podem tornar-se experiências difíceis e desestruturadoras em sua manifestações históricas e sociológica concretas. Quando acontece a interação, um indivíduo pode sentir que sua autoimagem retransmitida pelo outro - por meio de palavras, atitudes, comportamentos - é uma imagem desvalorizante, discriminatória ou até agressiva. Esta experiência pode perturbar e instalar no âmago de sua identidade uma dúvida sobre o seu real valor e o valor das metas que ele estabeleceu para si mesmo. A depreciação sistemática, afirmam os multiculturalistas, afeta pesadamente a autoestima de um indivíduo e acaba sendo interiorizada e instalada no âmago de sua identidade.

O respeito devido traduz uma necessidade humana, afirma o autor, que encontra na modernidade a origem da importância do reconhecimento e da identidade, quando a individualidade passa a ser tema de reflexão. As transformações no Antigo Regime significaram o desaparecimento da estrutura social hierárquica baseada na desigualdade por herança, em que a honra de alguns era um princípio imutável e inquestionável. Na modernidade, a honra é substituída pela dignidade, em seu sentido universal e igualitário, postuladas pelas sociedades democráticas. Essa mudança representou a introdução da política de reconhecimento igualitário, que tem se apresentado de forma distinta ao longo da história moderna na acepção de Taylor. A compreensão mais profunda da identidade revela sua estreita relação com o reconhecimento, cuja importância passa a ser essencial desde o nível pessoal ao social. 
Os laços entre identidade e reconhecimento demonstram a importância das discussões em torno do multiculturalismo, uma vez que a coexistência de culturas distintas exige o respeito às diferenças, tanto em relação à igualdade de condições de vida material quanto ao reconhecimento e à integridade das tradições, valores e formas de vida, possibilitando que os membros de grupos que foram discriminados possam reconhecer-se a si próprios e serem reconhecidos em sua integridade, dignidade e humanidade.

\subsection{A cidadania}

Segundo Hannah Arendt (1989, p. 12), o pensamento precisa estar enraizado na experiência e os homens “[...] só podem experimentar o significado das coisas por poderem falar e ser inteligíveis entre si e consigo mesmos”. Em suas reflexões, Arendt ressalta a importância dos espaços onde os homens renovem sua capacidade de pensar e agir, mas também preservem a grandeza da existência humana. Esses são os espaços públicos, que transformam a ação e o discurso individual em um mundo comum, no qual o homem pode perceber o outro e ser percebido, adquirindo visibilidade, força e possibilidade de ação. Juntos no espaço público, os homens experimentam o pertencimento a um mundo comum, em que eles podem agir e mudar. Esse mundo plural constrói a realidade e dá sentido à existência humana.

Ao refletir de modo livre sobre a obra de Hannah Arendt, Lafer (1999) conclui que é possível conceber a cidadania como "o direito a ter direitos", o fundamento sobre o qual é possível construir a igualdade e esta, para se realizar, requer acesso ao espaço público, pois é na organização do espaço público que os direitos serão construídos.

Em sua origem grega, cidadania significava ter direito à cidade, à comunidade organizada, da qual fazia parte apenas a aristocracia, sendo excluídos mulheres, servos, escravos e estrangeiros. Ao longo da história ocidental, a construção da cidadania adquire novo sentido no processo de formação do capitalismo. Em função de sua natureza histórica, a cidadania se ampliou e ultrapassou a cidade, 
traduzindo a utopia moderna de igualdade e liberdade preconizadas pelo Iluminismo (LEMOS, 2008).

Em aparente contradição com a ideia de universalização, que se efetiva pela imposição de valores e padrões nos níveis econômicos, sociais e culturais, as transformações históricas do Ocidente nos últimos cinco séculos não produziram a igualdade e a integração globais proclamadas, mas acentuaram diferenças, desigualdades e exclusões nos níveis local, nacional e mundial. O século passado trouxe questionamentos às teorias universalistas de direitos humanos e impôs a busca por propostas que viabilizassem transformações rumo a uma realidade social mais justa.

A sociedade moderna fundamentou a concepção de cidadania no princípio de igualdade dos indivíduos e na uniformidade de direitos entre eles. Com o propósito de uma abordagem que inclua a diversidade nas discussões sobre a cidadania, Santos (2003) diz que as conquistas significativas em direção aos direitos não conseguiram mudar o atual cenário mundial marcado pela segregação e disparidade social e econômica. Em sua concepção tradicional, os direitos humanos se baseiam

[...] em um bem conhecido conjunto de pressupostos, todos eles tipicamente ocidentais, designadamente: existe uma natureza humana universal que pode ser concebida racionalmente [e] a natureza humana é essencialmente diferente e superior à restante realidade. (SANTOS, 2003, p. 439).

\subsection{A constituição de grupos étnicos: a emergência da luta por direitos}

Muitos acordos e tratados buscaram regular e proteger minorias ao longo da história. Entretanto, tais medidas não alcançaram resultados que incluíssem os diversos grupos, nem eliminaram o tratamento injusto e discriminatório. Após a Segunda Guerra Mundial, surgiu a tendência liberal que creditava aos direitos humanos a solução dos conflitos das minorias, ou seja, a garantia dos direitos individuais - civis e políticos - que seria capaz de lidar com as questões de pertença 
étnica e nacional. Norteada por esse princípio, a Declaração Universal dos Direitos Humanos da ONU, de 1948, não contemplou os direitos específicos das minorias etnoculturais (KYMLICKA, 1995).

A noção de universalismo dos direitos humanos impõe os valores ocidentais, mas também pode ser usada a partir de uma perspectiva transformadora, como na sua expansão aos povos indígenas, aos afrodescendentes e aos imigrantes. Sob essa leitura, proposta por Santos (2003), os direitos humanos se ampliam e podem fundamentar reivindicações interétnicas e reconhecer a diversidade de cultura e valores. Ao adquirirem sentido de direitos coletivos ou diferenciados, um novo ordenamento jurídico desloca a centralidade do indivíduo para o grupo ou comunidade visando reparar injustiças. A partir do século XX, essa tendência pode ser vista em muitas medidas nos níveis nacional e internacional.

Após a Segunda Guerra Mundial, o reconhecimento da diversidade passou a fazer parte dos sistemas constitucionais dos Estados, compondo um cenário globalizado no qual atua uma rede internacional de organizações governamentais e não governamentais, ao lado de organismos transnacionais que apoiam as lutas das minorias de diferentes maneiras. Entretanto, apesar do caráter absoluto dos direitos individuais predominar em detrimento da regulamentação dos direitos coletivos inscritos nas novas legislações constitucionais,

[...] a busca de participação e reconhecimento de direitos coletivos é comum a praticamente todos os Estados latinoamericanos, que têm reinventado o sistema jurídico para reconhecer estas garantias coletivas e possibilitar novas perspectivas de vida local" (SOUZA FILHO, 2003, p. 103).

\subsection{O multiculturalismo e as políticas de reconhecimento}

Nas últimas décadas do século XX, as lutas e movimentos sociais locais se ampliam e se apoiam no espaço transnacional característico da realidade contemporânea, em que as diferenças já são consideradas. Nesse contexto, são traçados documentos e políticas que buscam o reconhecimento das diferenças. Entre os fatores que impulsionam tais transformações, ressurge a etnicidade que, baseada em 
um tipo de solidariedade construída, promove "[...] lutas de afirmação de direitos étnicos diferenciados no cenário das relações inter-étnicas globalizadas" (NEVES, 2003, p. 115). Em resposta a lutas e demandas dos grupos étnicos, definem-se ações, programas e estratégias políticas orientadas por valores desses grupos.

Santos e Nunes (2003, p. 29) lembram que diversas propostas e abordagens sobre o multiculturalismo visam ao "[...] reconhecimento e visibilidade das culturas marginalizadas ou excluídas da modernidade Ocidental” com suas histórias e diferenças. Reflexo das transformações nas sociedades pós-industriais, o multiculturalismo traduz a crise no projeto universalista da modernidade e expõe a questão da integração da diversidade no sistema social.

Segundo Kymlicka (1995), multiculturalismo designa as diferenças nacionais e étnicas, sem incluir as minorias e grupos sociais que estiveram excluídos historicamente, como mulheres, gays, lésbicas, portadores de necessidades especiais, que passam a fazer parte dos novos movimentos sociais. É, pois, o conceito de cultura como "etnia" e "nação", ou seja, uma comunidade com instituições em um território ou pátria, com uma linguagem e história específicas, que vai determinar essa concepção.

Em uma abordagem mais ampla do conceito, Semprini (1999) define o multiculturalismo como o resultado do encontro de culturas, etnias, religiões e outros grupos minoritários diferentes em um ambiente onde existe a imposição de um padrão monocultural. É preciso entender a emergência desse fenômeno no contexto monocultural de uma sociedade dominada por valores essencialistas e universalistas, representações de um Estado e uma cultura hegemônica. Essência do projeto da modernidade, o universalismo pressupõe uma ordem absoluta, com valores e princípios válidos para toda humanidade e encobre as diferenças, que historicamente se manifestam em genocídios, segregação e opressão ao longo do processo de colonização e expansão do capitalismo.

No nível global, a interdependência entre os Estados e os povos não resultou em solidariedade e coesão social. Ao refletir sobre a cidadania atual, Kymlicka (1995) acredita que existem outras formas de exclusão que não podem ser resolvi- 
das por meio da cidadania igualitária, já que indivíduos e grupos são excluídos não por sua posição socioeconômica, mas pela sua identidade sociocultural. Assim, a divisão clássica dos direitos da cidadania não funcionou no caso dos imigrantes culturalmente distintos, nem nos outros grupos historicamente excluídos da plena participação na cultura nacional, como negros, mulheres, minorias religiosas, gays e lésbicas. Alguns membros desses grupos continuam se sentindo excluídos da 'cultura comum' mesmo que possuam os direitos comuns da cidadania (KYMLICKA, 1995, p. 247).

\subsection{Multiculturalismo: o novo paradigma ético e o papel do direito}

Ao explicitar as contradições da modernidade, as reivindicações multiculturais colocam a "[...] transição de um paradigma político para um paradigma ético" (SEMPRINI, 1999, p. 161), ou seja, a ética se impõe aos domínios da esfera pública, por meio de ações mais humanas, pautadas na justiça real e subjetiva e no respeito e valorização dos indivíduos e grupos. O Direito passou a incluir as diferenças ao penetrar e a regulamentar a vida dos indivíduos e dos grupos; as reivindicações multiculturais se valem dos princípios de equidade para defender os interesses particulares dos grupos étnicos e minoritários (SEMPRINI, 1999).

Taylor (1994) acredita na possibilidade de garantir os direitos fundamentais prescritos nas constituições democráticas e, ao mesmo tempo, abranger as diferenças que emergem e se organizam nas culturas modernas por meio da revisão jurídica e da conquista de diretos. Kymlicka (1999, p. 265) afirma que os direitos diferenciados precisam ser garantidos constitucionalmente, pois as reivindicações dos grupos étnicos e nacionais “[...] são consistentes com os princípios liberais de liberdade individual e justiça social”. Para Santos e Nunes (2003, p. 57), o Direito pode participar na constituição ou resistência da ordem neoliberal, mobilizada tanto pelo Estado, quanto pelos movimentos sociais, ou seja, “[...] a produção do Direito torna-se [...] um processo sempre em aberto, protagonizado por uma diversidade de atores e em espaços sem fronteiras definidas" em que “[...] ONG's e movimentos sociais aparecem como mediadores cruciais entre diferentes formas de Direito e entre comunidades locais, o Estado nacional e organizações internacionais". 
Entre as minorias envolvidas, os grupos étnicos ressurgem com forte participação nas políticas de reconhecimento identitário. Esses grupos passam a significar o espaço de pertença, a que populações minoritárias se agarram como referência. Os indivíduos, ao se reconhecerem membros de um grupo étnico, reivindicam o direito à modernidade política, cívica e econômica, tornam-se sujeitos de direitos, mantendo-se vinculados à comunidade e à tradição. Nesse sentido, a discussão sobre a cidadania no multiculturalismo leva à questão do reconhecimento das minorias e suas identidades, entre elas as manifestadas pela etnicidade.

\subsection{A etnicidade}

A discussão em torno da etnicidade é importante para a compreensão do mundo atual. Estudos recentes sobre o tema buscam conhecer o processo pelo qual as diferenças culturais são codificadas e passam a determinar a categoria étnica, com base na qual os indivíduos constroem fronteiras étnicas e defendem as identidades por eles criadas, baseados em um tipo de solidariedade específica.

A partir da década de 1960, Fredrick Barth, antropólogo alemão, passa a considerar que a identidade étnica é construída e transformada com base nas interações de grupos sociais, no limite das relações e por meio de processos que incluem e excluem os indivíduos. Barth (apud POUTIGNAT; STREIFF-FENART, 1998) enfoca os processos pelos quais os grupos étnicos se formam, a partir das interações e diferenciações de suas fronteiras. Os grupos étnicos não são entidades socioculturais estáveis, fechadas e concretas, mas estabelecem contato cultural, garantindo uma contínua mobilidade das pessoas. As diferenças étnicas existem em decorrência dos limites entre os grupos.

Poutignat e Streiff-Fenart (1998) avançam em relação à teoria interacionista proposta por Barth ao articularem etnicidade a símbolos identitários, cuja formação se fundamenta na crença na origem comum voltada para o passado, representado pela memória coletiva. O conceito de etnicidade remete ao estudo dos processos 
[...] pelos quais os membros se identificam e são identificados pelos outros na base da dicotomização Nós/ Eles, estabelecida a partir de traços culturais que se supõem derivados de uma origem comum e realçados nas interações sociais (POUTIGNAT; STREIFF-FENART, 1998, p. 141).

São as fronteiras entre os grupos étnicos que definem a existência da etnicidade e não os aspectos culturais internos. Entretanto, é preciso analisar os processos pelos quais são construídos e transformados os limites entre os grupos étnicos, ou seja, o que caracteriza o processo de delimitação entre os grupos. É isso que faz Arruti, ao articular Antropologia e História no processo de formação quilombola numa comunidade étnica brasileira, Mocambo, situada em Sergipe.

No caso da formação identitária do Mocambo, Arruti (2006, p. 133) explica que a fronteira étnica que definiu essa comunidade resultou não da situação de contraste e diferença em relação aos outros grupos, mas a partir “[...] de uma realidade histórico-documental de um arranjo jurídico-administrativo, de uma política de bens escassos, demarcada pelos limites de atribuição da tutela estatal”. Foi resultado de um processo permeado de conflitos, disputas e aproximações que envolveu vários agentes mediadores, e que separou os membros do Mocambo (nós) dos outros grupos (eles).

O processo de fixação desses símbolos identitários corresponde à criação de lembranças e mitos fundadores, estabelecendo um ponto de origem que pode variar no tempo. Os grupos étnicos não possuem uma realidade essencial e imutável. No entanto, as diferenças étnicas fundamentam-se na continuidade de uma memória histórica baseada em mitos, lembranças e esquecimentos, que reconhece e fixa símbolos de acordo com as circunstâncias. Confirmando as reflexões acima sobre a associação entre identidade étnica e a origem e história comuns a serem resgatadas a partir da memória dos membros do grupo, Arruti (2006, p. 202) acredita que "[...] pode mesmo ser possível que tais memórias e tradições não existam simplesmente prontas a serem colhidas pelo pesquisador", pois os registros da memória nem sempre estão disponíveis.

Arruti (2006, p. 39) afirma que os grupos étnicos quilombolas são definidos a partir da reivindicação de uma identidade coletiva “[...] com base em fatores 
pretensamente primordiais". Porém, destaca o autor, nenhuma das características apontadas, tais como origem ou ancestrais comum, hábitos, rituais ou religiosidade compartilhados, vínculo territorial centenário, parentesco social generalizado, homogeneidade racial, “[...] está presente em todas as situações, assim como não há nenhum traço substantivo capaz de traduzir uma unidade entre experiências e configurações sociais e históricas tão distintas". A identificação étnica quilombola não foi feita a partir de uma lista de traços e símbolos culturais, como demonstra a experiência da comunidade do Mocambo.

\section{A emergência da etnicidade no Brasil a partir de 1980}

\subsection{A cidadania no Brasil}

Ao propor uma periodização da história do Brasil, Carvalho (2009) articula as diversas fases ao desenvolvimento dos direitos da cidadania. Para análise do presente artigo, toma-se o período pós-1930 para identificar a proeminência que passam a ter os direitos sociais pautados nas questões trabalhistas, enquanto os direitos civis e políticos passam por um período de instabilidade. Entre 1945 a 1964, os direitos políticos se ampliam e o país vive sua experiência de democracia, com a garantia dos direitos sociais e civis. O período seguinte, de 1964 a 1985, vive um atribulado momento pela imposição de um regime ditatorial, com a consequente restrição aos direitos civis e políticos e expansão dos direitos sociais. A partir de 1974, tem início um lento processo de abertura, correspondendo à retomada de oposição, incluindo movimentos partidários, sindicais e sociais. A mobilização de amplos setores ao final desse período, marcado pela luta das eleições diretas, representou a enorme força política da população que vai culminar com a redemocratização.

A Constituição Federal em 1988 foi o marco desse período. Fruto de amplas discussões com especialistas e setores organizados e representativos da sociedade, a Carta promoveu a expansão e garantia dos direitos sociais, ampliou os políticos e recuperou e inovou os civis. Todos esses avanços, porém, não são traduzidos na prática e os problemas sociais persistem expressos nas tensões atuais (CARVALHO, 2009). 
As transformações ocorridas das últimas décadas no Brasil confirmam as ideias propostas por Kymlicka (1995), quando este afirma que as democracias liberais buscam acomodar as diferenças culturais por meio da proteção aos direitos civis e políticos dos indivíduos, garantindo direitos comuns de cidadania. Cada vez mais se aceita que a diversidade cultural requer medidas legais ou constitucionais especiais acima dos direitos comuns de cidadania, os denominados direitos diferenciados em função do grupo.

No século XX, transformações na ordem mundial favoreceram a introdução de dispositivos constitucionais relativos aos direitos diferenciados.

Segundo Arruti (2006, p. 43)

[...] há um crescente consenso público internacional de que os reconhecimentos dos direitos das minorias não são simples questões de política discricionária ou de acordos pragmáticos, mas assuntos de direitos fundamentais.

Os direitos das minorias passam a fazer parte das discussões e decisões internacionais em direção a uma política de reconhecimento. Em muitos países, a emergência de identidades étnicas encontra no campo da conquista de direitos um caminho privilegiado para sua manifestação e reconhecimento.

A década de 1970 presencia o surgimento das mobilizações e manifestações indígenas no Brasil, no curso dos movimentos étnicos de vários países da América Latina. É o momento das assembleias indígenas e da consolidação de suas lutas, orientados pela solidariedade e pelas demandas dos grupos, que passam a pressionar politicamente. Apesar da diversidade de etnias indígenas, houve uma aglutinação desses grupos motivados por valores, significados e interesses comuns.

A partir da metade dos anos 1980, o processo de redemocratização latino-americana trouxe mudanças nas constituições dos Estados nacionais, com a introdução do reconhecimento da diversidade cultural e étnica. No Brasil, surge a tendência a um novo tipo de "política das diferenças" que institui os "direitos étnicos", garantindo direitos territoriais e/ou autonomia política jurídica aos povos indígenas e negros rurais (ARRUTI, 2006). 
Após três séculos de segregação, nas três últimas décadas do século XX, no curso de outros movimentos nacionais e internacionais das minorias, a população negra no Brasil dá início à conquista como sujeitos de direitos. Na década de 1970, aparecem vários estudos sobre comunidades negras rurais; entretanto, a ausência de uma base teórica consistente não permitia uma avaliação mais crítica da problemática negra. É apenas na década seguinte que as análises com essa temática, ao lidar com o conceito de etnicidade, dão início ao discurso que vai fomentar o movimento negro. O grande marco desses debates foi a aprovação do artigo 68 do Ato das Disposições Transitórias da Constituição Federal de 1988, cujo impacto, a partir de 1995, se faz notar por meio da ação do Estado ao promover mudanças na dimensão jurídica em resposta às demandas expressas nos movimentos sociais (ARRUTI, 2006).

\subsection{O movimento negro e o surgimento das políticas de reconhecimento no Brasil}

A consciência antirracista dos movimentos negros surge com a Frente Negra na década de 1930, ainda sob uma perspectiva universalista de integração e assimilação à cultura hegemônica branca, sem considerar a diversidade e os valores da população negra. Essa tendência predomina nas décadas seguintes. Apenas a partir de 1970, o Movimento Negro denuncia o preconceito e a discriminação cultivados ao longo da história brasileira e reivindica a aceitação da contribuição positiva da identidade negra, com suas características étnicas e culturais, ou seja, começa a assumir uma identidade específica. No entanto, apenas na década de 1980, ao longo do processo de redemocratização do país, surge espaço para que este movimento organize suas demandas e atue no âmbito do Estado, obtendo as primeiras respostas do poder público (D’ADESKY, 2009).

Após decreto presidencial, em 1987, fica estabelecido o Programa Nacional do Centenário da Abolição da Escravatura, a ser executado durante o ano de 1988. Nesse ano, a aprovação da Constituição Federal declara os direitos sociais e individuais, a liberdade, a segurança, o bem-estar, o desenvolvimento, a igualdade e a justiça como valores supremos de uma sociedade justa, fraterna, pluralista e sem 
preconceitos de origem, raça, sexo, cor, idade e sem qualquer forma de discriminação. A partir de então, uma série de iniciativas voltadas à população afrodescendente foi adotada pelos poderes constituídos e pela sociedade civil, conferindo visibilidade à questão negra no Brasil. Surgem espaços institucionais no âmbito federal com o objetivo de propor políticas públicas de ação e valorização dessa população, com forte atuação nos processos de regularização das áreas remanescentes de quilombos (SANT’ANNA; PAIXÃO, [1998]).

\section{A comunidade remanescente de quilombo do Mocambo}

A última Assembleia Nacional Constituinte trouxe as questões raciais e sociais do negro ao debate político, ao lado de demandas sociais fortalecidas. Entre as características da reforma constitucional brasileira está o reconhecimento da diversidade cultural e étnica nacional, manifestada nos direitos étnicos. Esses direitos abrem espaço

[...] para o reconhecimento dos direitos territoriais e/ou autonomia política e jurídica dos grupos indígenas [...] e negros rurais [...], assim como do direito a um tratamento distinto em relação às políticas públicas (ARRUTI, 2006, p. 65).

É nesse contexto que a Constituição Federal de 1988 institui em seu artigo 68 do Ato das Disposições Constitucionais Transitórias (ADCT) o reconhecimento de comunidades negras rurais com o seguinte texto: “[...] aos remanescentes das comunidades dos quilombos que estejam ocupando suas terras, é reconhecida a propriedade definitiva, devendo o Estado emitir-lhes os títulos respectivos" (BRASIL, 1988). O reconhecimento jurídico dessa categoria implicou a produção de "novos sujeitos políticos etnicamente diferenciados", afirma Arruti (2006, p. 67).

Apenas em 1995, o tema produziu seus impactos sociais e se expandiu por vários estados brasileiros, tornando-se assunto de destaque na imprensa, de discussão política e de estudos acadêmicos. A partir de então, essas comunidades passaram a ser incluídas nas medidas afirmativas, ao lado de povos indígenas, como também em outros projetos políticos (ARRUTI, 2006). 
A designação de "comunidades remanescentes de quilombos", dada pelo artigo constitucional, traz elementos e interpretações que merecem reflexão e análise, pois a escolha do termo no momento da Constituinte pautou-se em uma conceituação confusa e imprecisa como rótulo, cujo significado vai sendo ressemantizado nos anos seguintes em um cenário diversificado, marcado por mudanças políticas e mobilizações sociais no plano nacional e global. O termo escolhido não correspondia a um grupo definido ao qual se atribuísse aquela categoria jurídica. Assim, a aplicação do artigo à realidade social envolveu um trajeto sinuoso e complexo, que diz respeito à formação identitária de um grupo em um contexto de mobilizações sociais e articulações políticas.

Segundo Arruti (2006, p. 26), as comunidades remanescentes de quilombos constituem uma

[...] categoria social relativamente recente, representa uma força social relevante no meio rural brasileiro. [...] Organizadas em nível nacional em uma Coordenação com delegados [...], essas comunidades reivindicam, principalmente, a regularização de territórios sociais tradicionalmente ocupados, cujas origens remetem, em regra - não exclusivamente - ao período da escravidão.

Embora reconheça a importância do caráter situacional, relacional e político para a identificação dos grupos étnicos proposto pela teoria de Barth, Arruti (2006, p. 40) percebe limitações dessa conceituação, uma vez que a "autoatribuição, as fronteiras interétnicas, na contrastividade ou mesmo na situcionalidade identitária não dão conta da passagem entre o fenômeno de adscrição étnica (necessariamente local) do grupo (o etnônimo) e a sua adesão à categoria genérica e englobante" quilombola, de caráter jurídico-administrativo.

As comunidades "remanescentes de quilombos", como objeto jurídico-administrativo, foram criadas pelo Estado que, embora atue como figura central nesse processo, o faz ao lado de outros agentes, em função de mudanças nas relações e nos significados dos agentes e mediadores. Essas transformações são desdobramentos do cenário internacional, onde a pressão por uma revisão da maneira injusta pela qual os Estados lidaram com as diferenças tem produzido uma demanda pelo reconhecimento dos direitos das minorias. 
No contexto nacional do final dos anos 1980 e início dos 1990, a comunidade de Mocambo reivindicou o direito às terras nas quais habitavam há mais de 100 anos e contaram com o apoio de diversos atores e mediadores governamentais e não governamentais. Em 1997, a convite da Associação Brasileira de Antropologia (ABA), Arruti esboçou um laudo de identificação étnica para o reconhecimento oficial desta comunidade rural como remanescente de quilombo. Localizada às margens do Rio São Francisco, em Sergipe, Mocambo era composta então por 150 famílias afrodescendentes.

O reconhecimento de Mocambo envolveu as inter-relações, as interações e os conflitos que constituíram seu processo de diferenciação e identificação: a comunidade se tornou sujeito político no nível local e sujeito de direito no nível institucional jurídico e nacional. A partir do processo de reconhecimento oficial de Mocambo como remanescente de quilombos, emergiu um campo político na comunidade que trouxe transformações ao cenário local. A instituição desse campo político promoveu ações implementadas por diferentes atores, que influenciaram no reordenamento do território e nas regras de funcionamento do grupo. Muitos conflitos foram gerados por esse reordenamento do espaço físico e social, com a introdução de novas regras em relação ao sistema de trabalho, ao meio ambiente, à forma de ocupação e à formalização do controle por parte de uma associação de moradores local. Essa associação surge por exigência do Estado e o reproduz internamente, com “[...] a pretensão de instituir um ordenamento de caráter jurídico e uma soberania territorial” (ARRUTI, 2006, p. 322).

O processo de reconhecimento do Mocambo como "comunidade remanescente de quilombo" é um exemplo privilegiado da maneira pela qual a identidade étnica é socialmente construída e pode tornar-se instrumento na conquista de direitos e cidadania. A formação dessa identidade não acontece em um contexto isolado, abstrato e neutro, mas envolve uma complexidade de interações e fatores, como descreveu e analisou Arruti (2006). A partir de um ato jurídico, o processo de identificação étnica dos remanescentes de quilombos proporcionou um novo significado à situação vivida pela comunidade, na qual emergiu a solidariedade étnica do grupo que favoreceu a luta pelo reconhecimento. Cabe 
ressaltar que esse tipo de solidariedade não surge "naturalmente", mas é produzida em função de um conjunto de fatores e discursos que extrapolam os níveis local e nacional. A etnicidade é uma qualidade sempre disponível de ser ativada e mobilizada, mas as condições e manifestações em que emerge variam historicamente.

Ao tornar-se sujeito de direitos instituídos pelo ordenamento constitucional, Mocambo passou a reivindicar seus direitos até então inexistentes. Um dos elementos acionado para essas conquistas foi a afirmação da etnicidade. A categoria jurídica promulgada no artigo 68 disparou um processo que se dá em dupla mão. Para conquistar seus direitos, Mocambo ressurge em nome da afirmação da etnicidade e, ao mesmo tempo, ao lhe ser atribuída a classificação de grupo étnico, torna-se sujeito de direitos.

Sob uma abordagem crítica, Arruti (2006) afirma que é preciso superar os pressupostos teóricos que atribuem à identidade étnica o caráter de manipulação ou invenção orientada por algum interesse. Para este autor, tais abordagens nada esclarecem, pois os interesses representam as aspirações do grupo e incluem a luta por recursos, mas inserem também as motivações de ordem moral, por meio da qual o grupo busca respeito e dignidade, enfim, o reconhecimento.

Após o reconhecimento oficial, Mocambo experimentou intensas transformações, pelas quais o grupo se tornou uma categoria étnica, social e jurídica em um território especifico. Tais mudanças afetaram o espaço e a organização sociopolítica da comunidade, que se institucionalizou, constituindo uma organização social e territorial. Mocambo adquiriu visibilidade, passando a ser vista, então, pelo Estado e pela sociedade como um sujeito de direitos e, portanto, integrante da cidadania em moldes contemporâneos.

As questões étnicas são essenciais para o reconhecimento de grupos minoritários até então excluídos e discriminados no contexto do multiculturalismo, pois o respeito das identidades, entre elas as manifestadas pela etnicidade, apresenta-se como importante caminho para a conquista da cidadania. 


\section{Considerações finais}

Nas discussões contemporâneas, existe um esforço de conciliar o universalismo e a diversidade. A política de reconhecimento igualitário, fundamentada na dignidade universal dos direitos a todos os cidadãos e inscrita na concepção tradicional de cidadania, torna-se base para o reconhecimento da diversidade, pautada no respeito ao grupo ou indivíduo em sua identidade cultural, étnica e nacional. Propõe-se uma nova concepção de cidadania que inclui as diferenças dos grupos minoritários, ou seja, os Estados e os respectivos ordenamentos jurídicos passam a garantir as diferenças até então negligenciadas ou deslocadas para a esfera privada. Em uma nova concepção de justiça, a cidadania contemporânea tem o sentido de conjugar os direitos fundamentais e os direitos específicos (SANTOS, 2003; KYMLICKA, 1995; TAYLOR, 1994).

A cidadania contemporânea adquire novo significado, em que o ideal de igualdade universal se amplia no sentido do respeito à diferença e às reivindicações das minorias: a cidadania diferenciada ou multicultural. As demandas das minorias reunidas em movimentos e organizações encontram no Direito e em seu garantidor, o Estado, um instrumento essencial para a conquista da cidadania. Entre as diversas expressões dessas reivindicações, surge a etnicidade.

A identidade étnica constitui um dos processos de interações sociais por meio dos quais são ressaltadas as diferenças entre os indivíduos e grupos. A pertença étnica torna-se fonte de significado na constituição de sujeito social capaz de agregar lealdades e lutas por direitos diferenciados, apresentando-se como forte influência à instituição da cidadania na realidade multicultural. Por meio de ações e programas, as estratégias políticas representam repostas às demandas dos grupos étnicos e seus direitos.

O caso da comunidade remanescente de quilombo do Mocambo, analisado a partir dos estudos de Arruti (2006), revela dois aspectos que merecem ser destacados: o primeiro torna-se um exemplo da maneira pela qual as identidades étnicas são construídas e o segundo demonstra como a constituição da identidade étnica de um grupo consiste em um caminho para a conquista de direitos. $\mathrm{O}$ ressurgimento dos remanescentes de quilombos como grupo étnico e sujeitos de 
direitos, em Mocambo, é acompanhado de novas classificações no plano do ordenamento jurídico e do Estado, que reconhecem oficialmente uma identidade e, ao mesmo tempo, criam essa categoria social.

Os remanescentes de quilombos emergem como grupo étnico com base em critérios subjetivos e contextuais, inscritos em um cenário de oposição e diferença e se associam à afirmação da identidade étnica. A delimitação do conteúdo de remanescentes de quilombos é bastante plástica, resultando do conjunto de agentes, mediadores, instituições e o Estado que possibilitaram a interpretação do artigo constitucional e, portanto, contribuíram para a ressemantização do tema, sua aplicação e seus efeitos, como demonstrou Arruti (2006) em seu instigante estudo.

Ao serem reconhecidos como remanescentes de quilombo, esses grupos passam a ser "[...] símbolo de uma identidade, de uma cultura e, sobretudo, de um modelo de luta e militância negra” (p. 82). A política das diferenças inclui, além da garantia material, o reconhecimento e espaço para a construção da identidade das minorias, sendo capaz de promover coesão e visibilidade a esses grupos. É preciso afirmar uma identidade negra e garantir a terra. Após a adesão ao rótulo "remanescentes de quilombos" os membros do Mocambo descobriram-se parte da cultura negra e merecedores de direitos, adquirindo visibilidade social: tornaram-se cidadãos.

O cenário contemporâneo se configura pela tendência à internacionalização e ao mesmo tempo pela afirmação da diferença. Esse aparente paradoxo acontece em meio à definição de uma política multicultural, que coloca em discussão os pressupostos da democracia e o novo sentido de cidadania, em resposta a uma realidade diversificada que se organiza e reivindica. A partir das lutas dos diversos grupos minoritários nacionais e étnicos, o multiculturalismo exige a incorporação de uma política, por meio da qual a questão da identidade é essencial para a conquista da cidadania. Nesse sentido, identidade étnica e cidadania se articulam. A etnicidade torna-se uma referência existencial significativa para os indivíduos e grupos na construção da identidade e do reconhecimento, que implicam a conquista de direitos e da cidadania. A valorização da diferença faz emergir a construção das identidades, entre elas a identidade étnica, que ressurge com força e sentido para a conquista dos direitos na realidade contemporânea. 
O reconhecimento da diversidade é o primeiro passo para a construção de uma cidadania efetiva. O grande desafio das sociedades multiculturais é tornar possível a convivência entre grupos de culturas, nacionalidades e etnias variadas, a partir de dois discursos que buscam coadunar o universalismo e a diversidade visando a redução das injustiças, da opressão e, assim, o reconhecimento e preservação dos grupos minoritários.

A sociedade moderna fundamentou a concepção de cidadania no princípio de igualdade dos indivíduos e na uniformidade de direitos entre eles. São as transformações históricas da modernidade que permitem o surgimento do espaço em que se dará a luta e a conquista dos direitos. Em função de seu caráter histórico, a cidadania precisa ser entendida no processo de formação e dinâmica de uma determinada realidade. Novas práticas, concepções e direitos passam a constituir a cidadania contemporânea. Antes baseada em direitos iguais e comuns a todos, a cidadania que emerge nas últimas décadas do século XX é construída com base nos direitos diferenciados em função das demandas das minorias, em um ambiente complexo e diversificado, onde a constituição dos grupos étnicos adquire um papel fundamental.

\section{Multiculturalism and ethnicity: quilombolas and the construction of citizenship in Brazil contemporary}

\section{Abstract}

This article seeks to analyze the historical relation between ethnicity and citizenship in the multiculturalism context from the last three decades of the twentieth century, particularly in Brazil, in order to identify new concepts and experiences of citizenship that results from demands for recognition of diversity and social achievement, political and legal. Before based on equal rights and common to all, contemporary citizenship is built on differentiated rights of minorities.

Keywords: Multiculturalism. Ethnicity. Citizenship. Quilombos remnants. 


\section{Referências}

ARENDT, Hannah. A condição humana. Rio de Janeiro: Forense Universitária, 1989.

ARRUTI, M. J. Mocambo: antropologia e história do processo de formação quilombola. Bauru: Edusc, 2006.

BRASIL, Constituição (1988). Constituição da República Federativa do Brasil. Brasília: Senado Federal, 1988.

CARVAlHO, J. M. Cidadania no Brasil: o longo caminho. Rio de Janeiro: Civilização Brasileira, 2009.

D’ADESKY, J. Pluralismo étnico e multiculturalismo: racismos e antirracismos no Brasil. Rio de Janeiro: Pallas, 2009.

KYMLICKA, W. Cindadanía multicultural: una teoria liberal de los derechos de las minorias. Madrid: Paidós, 1995.

LAFER, C. A reconstrução dos direitos humanos: a contribuição de Hannah Arendt. Estudos Avançados, Rio de Janeiro, v. 11, n. 30, p. 55-65. Disponível em: $<$ http://www.scielo.br/pdf/ea/v11n30/v11n30a05.pdf>. Acesso em: 25 nov. 2010.

LEMOS, P. R. Os novos movimentos sociais e a cidadania. In: LEMOS FILHO, A. (Org.). Sociologia geral e do direito. Campinas: Alínea, 2008. p. 333-346.

NEVES, L. J. O. Olhos mágicos do sul (do sul): lutas contra-hegemônicas dos povos indígenas no Brasil.. In: SANTOS. B. S. (Org.). Reconhecer para libertar. Rio de Janeiro: Civilização Brasileira, 2003. p. 112- 151.

POUTIGNAT, P; STREIFF-FENART, J. Teorias da etnicidade. São Paulo: UNESP, 1998.

SANT'ANNA, W.; PAIXÃO, M.. Muito além da senzala: ação afirmativa no Brasil, [1998] Disponível em: <http://www.ibase.br/paginas/wania.htm> Acesso em: 20 out. 2010.

SANTOS, B. S; NUNES J. A. Introdução: para ampliar o cânone do reconhecimento. In: SANTOS. B. S. (Org.). Reconhecer para libertar: os caminhos do cosmopolitismo multicultural. Rio de Janeiro: Civilização Brasileira, 2003. p. 25-68. 
106 Univ. Hum., Brasília, v. 8, n. 1, p. 83-106, jan./jun. 2011

SANTOS, B. S. Por uma concepção multicultural de direitos humanos. In:

(Org.). Reconhecer para libertar: os caminhos do cosmopolitismo multicultural. Rio de Janeiro: Civilização Brasileira, 2003. p. 428-461.

SEMPRINI, A. Multiculturalismo. Bauru: EDUSC, 1999.

SOUZA FILHO, C. F. M. Multiculturalismo e direitos coletivos. In: SANTOS. B. S. (Org.). Reconhecer para libertar. Rio de Janeiro: Civilização Brasileira, 2003. p. 73-109.

TAYLOR, C. A política de reconhecimento. In: GUTMAN, A (Ed.). Multiculturalismo: examinando a política de reconhecimento. Lisboa: Piaget, 1994. p. 45-94.

WOODWARD, K. Identidade e diferença: uma introdução teórica e conceitual. In: SILVA, T. T. (Org.). Identidade e diferença: a perspectiva dos estudos culturais. Petrópolis: Vozes, 2000. p. 772. 